\title{
DE LOS FUSILES A LAS URNAS. FET-JONS ANTE LAS ELECCIONES MUNICIPALES (NON NATAS) DE 1946
}

\author{
From the rifles to the polls. FET-JONS before \\ the (non natas) municipal elections of 1946
}

\author{
CARLOS DOMPER LASÚS \\ Universidad de Zaragoza \\ carlosdomper82@gmail.com
}

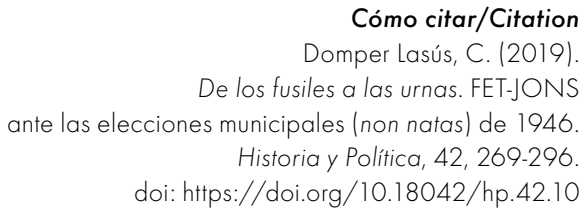

(Recepción: 24/03/2018; evaluación: 03/05/2018; aceptación: 02/07/2018; publicación: 13/12/2019)

\section{Resumen}

Este artículo analiza el proceso a través del cual Falange articuló su participación en las elecciones a concejales de representación familiar cuya celebración fue inicialmente fijada por el Gobierno para marzo de 1946. La base empírica del trabajo se asienta en documentación custodiada en el Archivo General de la Administración y procedente de dos órganos institucionales de FET-JONS: la Vicesecretaría General de Ordenación Social y el conjunto de jefaturas provinciales del Movimiento. La información obtenida de estas fuentes se inserta en el marco de la adaptación de FET-JONS y del propio régimen a la nueva comunidad internacional surgida de la derrota de las potencias del Eje en 1945 y se utiliza para describir con detalle los mecanismos que articuló Falange para intervenir en todas las fases de la organización de las citadas elecciones. El artículo concluye que, pese a las dificultades por las que atravesó desde mediados de 1945, Falange no permaneció pasiva ante la convocatoria electoral de 1946. Por el contrario, reaccionó de inmediato con el objetivo de no salir malparada de semejante coyuntura y, a la vez, aprovechar dichas elecciones 
para consolidar su poder. La Organización Sindical Española fue la encargada de llevar a cabo dicha intervención. La forma en la que lo hizo puso de manifiesto que a finales de 1945 el partido gozaba de un poderoso aparato institucional perfectamente arraigado dentro del régimen y con una gran coordinación entre los organismos nacionales y los periféricos.

\title{
Palabras clave
}

Elecciones; dictadura; franquismo; fascismo; Falange.

\begin{abstract}
This paper deals with the process through which Falange got involved in the organization of the elections to the representatives of the family heads at the councils, whose celebration was initially set by the Government by March 1946. The empirical basis of the work is based on records housed in the Archivo General de la Administración and coming from two institutional bodies of FET-JONS: the Vicesecretaría General de Ordenación Social and the provincial headquarters of the Movement. The information obtained from these primary sources is inserted in the framework of the adaptation of FET-JONS and the regime itself to the new international community that emerged from the defeat of the Axis powers in 1945. In addition, this information is used to describe in detail the mechanisms articulated by the Falange to intervene in all phases of the organization of the aforementioned elections. The paper concludes that, despite the difficulties it went through since mid1945, Falange did not remain passive faced with the 1946 electoral call. On the contrary, it reacted immediately with the aim of not being negatively affected by those elections and, at the same time, taking advantage of them to consolidate its power. The Spanish Trade Union Organization was in charge of carrying out this intervention. The way it coped with such a task showed that, by the end of 1945, the Party enjoyed a powerful institutional apparatus perfectly rooted within the regime and with great coordination between national and peripheral bodies.
\end{abstract}

\section{Keywords}

Elections; dictatorship; Francoism; fascism; Falange. 


\section{SUMARIO}

I. INTRODUCCIÓN. II. LA ORGANIZACIÓN DE LA INTERVENCIÓN ELECTORAL DE FET. III. EL CONTROL DE LAS JUNTAS PROVINCIALES DEL CENSO. IV. LA DEPURACIÓN DE LOS CENSOS ELECTORALES. V. EL CONTROL DE LAS CANDIDATURAS. LAS DIFERENCIAS ENTRE EL PARTIDO Y LA ORGANIZACIÓN SINDICAL. VI. CONCLUSIONES. Bibliografía.

\section{INTRODUCCIÓN'}

Hasta hace muy pocos años, la historia de FET-JONS ha sido predominantemente descrita y explicada como la de un fracaso sin paliativos. A pesar del rápido crecimiento que experimentó la formación gracias a la movilización producida por la guerra, la gran mayoría de la historiografía señalaba cómo el partido único español había sido incapaz de hacerse con el control del Estado, carecía del apoyo de la población y estaba controlado por representantes de las anteriores élites dirigentes conservadoras ${ }^{2}$. Dentro de esta línea interpretativa de la historia de FET-JONS, el momento clave que permitía certificar la defunción social y política del partido se situaba en 1945.

Como es de sobra conocido, en julio de 1945 el régimen franquista tomó diversas medidas de carácter político que le permitiesen adaptarse al nuevo contexto internacional surgido de la derrota de los fascismos, sin por ello renunciar a un ápice de su poder ${ }^{3}$. Entre esas medidas destacaron la aprobación del Fuero de los Españoles, la Ley de Bases del Régimen Local, la eliminación de la obligación de hacer el saludo romano o, unos meses más tarde, la aprobación de la Ley de Referéndum. Sin embargo, las decisiones adoptadas en aquel momento por el Gobierno que mejor sirvieron al relato del fracaso de FET-JONS fueron otras. Por un lado, la pérdida del rango ministerial de la Secretaría General del Movimiento. Por otro, la cesión del

1 El autor es miembro del equipo de trabajo del proyecto HAR2017-85967-P «El Servicio Universitario del Trabajo (SUT) en la España de Franco. Una perspectiva europea comparada (1950-1970)», financiado por el Ministerio de Economía, Industria y Competitividad. Deseo agradecer a Julián Sanz Hoya que me facilitase varios de los documentos utilizados para la redacción de este artículo.

2 Sanz Hoya (2013): 47.

3 Molinero e Ysas (2008): 14. 
control de la Vicesecretaría General de Educación Popular al católico José Ibánez Martín, por aquel entonces ministro de Educación.

De acuerdo con el citado relato, ese apartamiento de FET-JONS de la primera línea política se vio complementado por otro suceso que volvía a incidir en la debilidad del partido único español. Nos referimos a su supuesta absorción por el Estado gracias a la generalización del proceso de unificación de los cargos de gobernador civil y jefe provincial del Movimiento. Así, al colocar al partido bajo el control del Ministerio de la Gobernación, el régimen le arrebató la capacidad de nombrar y, por tanto, de controlar a sus jefes provinciales que habrían quedado sometidos al poder del Ministerio de la Gobernación ${ }^{4}$.

En los últimos años, nuevos estudios tanto de ámbito nacional como de temática local han mostrado una realidad de FET-JONS bastante diferente a la dibujada por el relato historiográfico al que acabamos de referirnos. Por lo que se refiere a la primera, los estudios recientes sobre las décadas de 1950, 1960 y 1970 muestran el peso y la relevancia de las posiciones falangistas en la política nacional del régimen durante aquellos años ${ }^{5}$. Con respecto a la unificación de los cargos de gobernador civil y jefe provincial del Movimiento, los recientes trabajos de Martí Marín y Julián Sanz Hoya han puesto de manifiesto una realidad bien distinta a la del sometimiento de FET-JONS por parte del Estado ${ }^{6}$. De hecho, estos autores han señalado que la mayoría de los gobernadores civiles designados desde entonces pertenecían al partido y aprovecharon su posición para impulsar el asalto falangista a los ayuntamientos y diputaciones, asegurando a FET-JONS el control político de la Administración Periférica del Estado al menos hasta los ańos sesenta7.

Este artículo se sitúa en esa segunda línea interpretativa de la historia de FET-JONS y analiza el proceso a través del cual el partido articuló su participación en las elecciones a concejales de representación familiar que, en un primer momento, fueron fijadas por el Gobierno para 1946. De este modo, trataremos de mostrar el gran poder que, incluso en el momento que más difíciles tuvo las cosas, albergó el partido único español gracias a la extensión y buen funcionamiento de sus extensos aparatos burocráticos. Por lo tanto, en las siguientes páginas describiremos con el máximo detalle que permiten las fuentes de las que disponemos las acciones que desarrolló FET-JONS con dos objetivos. Por un lado, garantizarse una posición de privilegio en los órganos institucionales

Sanz Hoya (2014): 194-195.

Sanz Hoya (2013): 49.

Sanz Hoya (2010): 18-20 y (2014): 193-212; Marín (2013b): 270-279.

Sanz Hoya (2014): 211. Martí Marín también ha subrayado esta idea en Marín (2013a: 234-235). 
encargados de organizar las elecciones. Por otro, y como consecuencia del primero, poder intervenir en las fases decisivas de dicho proceso de organización.

A decir verdad, esta vía de aproximación al estudio de los partidos únicos no ha sido muy utilizada por los historiadores de las dictaduras europeas del siglo xx. Bajo nuestro punto de vista, esto puede deberse a dos razones. En primer lugar, a diferencia de lo ocurrido en la ciencia política, los historiadores no han prestado mucha atención al estudio de los procesos electorales en las dictaduras, por entender que dichas elecciones no eran más que actos de carácter propagandístico ${ }^{8}$. En segundo lugar, la documentación primaria relativa a este tipo de actuaciones de los partidos únicos no es muy abundante y suele ser difícil de localizar? ${ }^{9}$. Con relación al caso español, las referencias a la actuación de FET-JONS en los procesos electorales organizados por la dictadura son prácticamente inexistentes ${ }^{10}$.

La base empírica de este artículo se asienta en documentación procedente de dos órganos institucionales de FET-JONS y custodiada en el fondo de Presidencia del Archivo General de la Administración de Alcalá de Henares. El primero de esos organismos es la Vicesecretaría General de Ordenación Social, dependiente de la Delegación Nacional de Sindicatos. El segundo lo constituyen el conjunto de jefaturas provinciales del Movimiento dependientes de la Delegación Nacional de Provincias. En general, se trata de resúmenes de reuniones de coordinación, instrucciones enviadas tanto a las jefaturas provinciales como locales del Movimiento, correspondencia con la Junta Central del Censo Electoral, informes sobre el grado de cumplimiento de las instrucciones recibidas y sobre el éxito de la estrategia implementada por el partido.

Con el fin de poder abordar todos los aspectos a los que hemos hecho referencia con la mayor claridad expositiva posible, el artículo se divide en los siguientes apartados. En primer lugar, se explica cómo se decidió la participación del

8 Un balance sobre las investigaciones realizadas en relación con las elecciones organizadas por las dictaduras del siglo xx puede encontrarse en Jessen y Richter (2011). Con respecto a las dictaduras del sur de Europa durante el siglo xx véase Moreno Fonseret (2003).

9 Esa es muy posiblemente la razón por la que solo hemos podido localizar tres trabajos que abordan directamente la participación de un partido único en la organización de las elecciones celebradas por una de las dictaduras europeas del siglo xx, Swearer (1961): 136-137; Braga da Cruz (1988): 194-215, y Reis Santos (2011): 130-141 y 144-163.

10 Véase Domper Lasús (2017). En su libro sobre los ayuntamientos franquistas en Cataluña, Martí (2000) también hace muchas referencias a la labor desarrollada por FET en la organización de las elecciones municipales. 
partido en las elecciones previstas por el Gobierno para 1946 y se contextualiza esa decisión en el marco de la complicadísima situación por la que atravesaba el partido a la altura de la segunda mitad de 1945. Posteriormente, se analizan los pasos que dio el partido para lograr representación en las juntas provinciales del censo electoral. A continuación, se explica cómo intervino en la conformación de los censos electorales de cabezas de familia. Finalmente, se aborda el plan disenado por la Organización Sindical para que FET-JONS pudiera controlar también el proceso de nominación de candidatos.

\section{LA ORGANIZACIÓN DE LA INTERVENCIÓN ELECTORAL DE FET}

Tras la aprobación en julio de 1945 de la Ley de Bases del Régimen Local, que preveía la celebración de elecciones trienales por tercios de representación para la renovación de los concejales, se levantó una gran expectación ante el momento y las circunstancias bajo las que se convocarían esos comicios. Sin embargo, la expectación no fue la única reacción de la sociedad franquista ante la futura convocatoria electoral. Entre muchas personas y entre la mayoría de las autoridades, esas elecciones despertaron también temor con respecto a las consecuencias políticas y sociales que las mismas podrían tener sobre el régimen.

Obviamente, Falange no fue ajena a este ambiente. De hecho, si uno revisa los partes de información que los jefes provinciales del partido enviaban mensualmente a la Delegación Nacional de Provincias descubrirá de inmediato dos cosas. En primer lugar, que, independientemente de la provincia a la que correspondan, los redactados durante el verano y el otońo de 1945 se hallan plagados de rumores sobre el asunto. En segundo lugar, que muchos de esos rumores no hacían sino reflejar los propios temores de los líderes falangistas que redactaban dichos partes y que ponían en boca de la «masa» o del "pueblo» la preocupación e inquietud que la celebración de esas elecciones les provocaba.

Un ejemplo bastante significativo de esta realidad lo encontramos en el parte mensual correspondiente al mes de julio de 1945 redactado por el jefe provincial del Movimiento de Barcelona. En dicho informe, Correa Veglison afirmaba que corría el rumor de que «el próximo mes de agosto se celebraran elecciones municipales». Frente a estos rumores, el jefe provincial del partido dibujaba la existencia de dos corrientes de opinión. Por un lado, la posibilidad de esa convocatoria había causado «gran regocijo entre el elemento rojo, ya que creen que estas elecciones se celebraran por presiones del exterior y que podrán votar todos los que lo deseen a quien quieran». Por otro lado, entre «el 
elemento adicto a nuestro régimen» existían muchas dudas sobre cómo se organizarían esas elecciones y las posibles consecuencias de las mismas, "pues se cree que si fueran efectivamente elecciones libres vendría el caos a nuestra patria $»^{11}$.

No obstante, la preocupación por los efectos que la celebración de esas elecciones pudiesen provocar no solo en el régimen sino también en el poder que FET-JONS ostentaba dentro de la estructura institucional del mismo no se restringió únicamente a los cuadros provinciales del partido. Por el contrario, esa preocupación latía con fuerza en el seno de los principales órganos nacionales de dirección de FET-JONS. De hecho, así se desprende de la lectura de la circular confidencial 174, enviada por Rodrigo Vivar Téllez, vicesecretario general del Movimiento, a las jefaturas provinciales del partido el 22 de agosto de $1945^{12}$.

En dicha circular el vicesecretario general explicaba a los jefes provinciales del mismo los principales retos a los que se enfrentaba su organización una vez terminada la II Guerra Mundial. Entre los diferentes desafíos que debía afrontar Falange, uno de los principales era el control de las elecciones municipales que iban a comenzar a organizarse en España. "Terminadas las leyes fundamentales que regulan la intervención de todos los españoles en la vida pública — decía Vivar Téllez- se aproxima la primera consulta electoral como consecuencia de la implantación de la nueva Ley de Bases de la Administración Local que aprobaron las Cortes». En este sentido, el líder falangista destacaba que FET-JONS debía de preparar debidamente esas elecciones, pero sobre todo indicaba que «esa labor preparatoria [...] ha de caracterizarse por su discreción y por la mayor eficacia del servicio»" ${ }^{13}$.

Sin embargo, estas elucubraciones y afirmaciones genéricas sobre la necesidad de controlar los futuros comicios por parte del partido se convirtieron en acciones concretas a partir del 4 de octubre de 1945. Ese día, el Boletín Oficial del Estado publicó el Decreto de 29 de septiembre de 1945 que daba

11 Parte mensual del jefe provincial del Movimiento de Barcelona, julio 1945. Archivo General de la Administración (en adelante AGA) (9) 51/20663

12 Rodrigo Vivar Téllez había sido gobernador civil de Almería entre 1940 y 1942 y de Vizcaya entre 1942 y 1944 . Pese a su bajo perfil político y escaso predicamento entre sus propios camaradas, que lo consideraban un "neofalangista" alejado de los "camisas viejas» que habían dominado el partido (Thomàs, 2001: 340), se convirtió en la máxima autoridad del mismo después de Franco tras no cubrirse la vacante dejada por el cese de Arrese, su mentor, al frente de la Secretaria General en julio de 1945. Rodríguez Barreira (2007): 256.

13 Circular confidencial número 174 de la Vicesecretaria General del Movimiento, 22 de agosto de 1945. AGA (9) 51/20739. 
instrucciones para la formación del Censo de Vecinos Cabezas de Familia con el objetivo de «preparar, en el plazo más breve posible, lo necesario para que puedan verificarse elecciones municipales en todo el territorio de la nación $»^{14}$. Este decreto fue interpretado como el pistoletazo de salida del régimen al proceso de organización de las primeras elecciones a concejales del tercio familiar. De hecho, en aquel momento la celebración de esas elecciones estaba prevista por el Estado para «la segunda quincena del mes de marzo del año próximo [1946]» de acuerdo con una orden de servicio de la Vicesecretaría General de Ordenación Social ${ }^{15}$.

Este es el contexto en el que hay que situar la reunión que tuvo lugar en la Secretaría General del Movimiento durante la primera mitad del mes de octubre de 1945 para organizar el mecanismo a través del cual FET-JONS intervendría en las elecciones convocadas para marzo de 1946. Dicha reunión, estuvo presidida por el vicesecretario general del Movimiento, Rodrigo Vivar Téllez, y a ella asistieron, al menos, el delegado nacional de Sindicatos, Fermín Sanz Orrio, y el vicesecretario nacional de Ordenación Social, José María de Olazábal ${ }^{16}$. El primero había sido uno de los fundadores de Falange en Navarra, aunque su condición de «camisa vieja» no le impidió formar parte de la directiva de la Asociación Católica Nacional de Propagandistas. Tras ocupar varios cargos dentro del partido y ejercer como gobernador civil, fue nombrado ministro de trabajo tras la destitución de José Antonio Girón de Velasco en $1957^{17}$. El segundo era uno de aquellos tradicionalistas que defendieron desde el primer momento la integración del tradicionalismo en FET. Desde muy pronto se integró en los puestos de mando de la Organización Sindical, sumando a ello su actuación como gobernador civil y jefe provincial del Movimiento de Las Palmas de Gran Canaria y procurador en Cortes durante la primera y segunda legislatura ${ }^{18}$.

14 Decreto de 29 de septiembre de 1945, Boletín Oficial del Estado (en adelante BOE), núm. 277, 4-10-1945, p. 2114.

15 Orden de servicio número 53 de la Vicesecretaria General de Ordenación Social. 13-10-1945. AGA (9) 51/18984. Ruiz Carnicer (1999: 259), ya apuntó esta fecha.

16 Todos los datos que tenemos sobre este encuentro proceden de un informe que este último envió a los dos primeros el 15 de noviembre de 1945 AGA (9) 51/18984. El encuentro también es mencionado por Fermín Sanz Orrio en un informe sobre las elecciones municipales que le envió al vicesecretario general del Movimiento el 17 de noviembre de 1945. AGA (9) 51/18984.

17 Las memorias de Sanz Orrio fueron editadas por su hija hace unos ańos en SanzOrrio Arraiza (2009).

18 ABC de Madrid, 28-12-1945, p. 23, y Giménez Martínez (2012): 491. 
Las principales conclusiones a las que llegaron los presentes en aquel encuentro fueron dos. En primer lugar, era necesario evitar que a las elecciones para elegir a los concejales por el tercio de representación familiar se les diese por parte de «elementos indiferentes u hostiles un matiz político del que carecen por ser puramente administrativas». En segundo lugar, Falange debía conseguir en las elecciones para dicho tercio «una mayoría de concejales afecta al Movimiento» ${ }^{19}$. De hecho, habiendo transcurrido solo tres meses desde su apartamiento del primer plano de la vida política nacional, en Alcalá 44 tenían muy claro que lograr esto era fundamental porque de lo contrario el partido podría perder parte del gran poder que tenía en la Administración periférica del Estado ${ }^{20}$.

No obstante, en la citada reunión no solo se definieron los objetivos de la intervención de FET en las venideras elecciones a concejales de representación familiar. Además, también se acordaron tanto el organismo que se encargaría de ejecutar la operación como el procedimiento que se utilizaría para materializar esos objetivos ${ }^{21}$. Por lo que respecta al primero de estos dos aspectos, el vicesecretario general del Movimiento encargó a la Organización Sindical, que el año anterior ya había organizado con éxito las primeras elecciones sindicales que tuvieron lugar bajo el franquismo ${ }^{22}$, la implementación del dispositivo necesario para "alcanzar los objetivos acordados en la reunión", autorizándola a dictar «las ordenes que se estimaran convenientes a tal efecto». De hecho, este encargo oral fue posteriormente refrendado por escrito a través del oficio 40220 de la Secretaría Nacional del Movimiento de 30 de octubre de 1945.

Con relación al mecanismo a través del cual el partido debía articular su intervención en las elecciones, los congregados decidieron que tendría tres fases. Primero, la Organización Sindical debía lograr su presencia en las juntas provinciales y municipales del censo, que como veremos eran una institución clave en la organización del proceso electoral. Después, una vez representada en dichos organismos, FET-JONS debería de lograr la depuración del Censo

19 Informe enviado por el vicesecretario nacional de Ordenación Social al delegado nacional de Sindicatos y al vicesecretario general del Movimiento el 15 de noviembre de 1945. AGA (9) 51/18984.

20 Este temor aparece también reflejado en Miranda y Pérez (1992): 140-141.

21 Toda la información al respecto que utilizamos procede del informe enviado por el vicesecretario nacional de Ordenación Social al delegado nacional de Sindicatos y al vicesecretario general del Movimiento el 15 de noviembre de 1945. AGA (9) 51/18984.

22 Véase Cue (1977) y Martínez Ovejero (2008). 
de Vecinos de Cabezas de Familia con una interpretación exacta y rigurosa del Decreto de 29 de septiembre de 1945. Finalmente, Falange debía ser capaz de conseguir dos objetivos. En primer lugar que dichas juntas proclamaran a los candidatos adecuados. En segundo lugar, que esos candidatos obtuvieran la mayoría de los votos emitidos.

No obstante, a pesar de que todas estas decisiones a las que estamos haciendo alusión fueron tomadas por instituciones nacionales del partido, la explicación más perspicaz y explícita que hemos encontrado de las motivaciones que latían tras la adopción de las mismas procede del ámbito provincial. En concreto, la formuló el gobernador civil y jefe provincial del Movimiento de Málaga, Manuel García del Olmo, en una circular que envió a los jefes locales de la provincia en octubre de 1945 . En ese texto, el notario sevillano ${ }^{23}$ daba instrucciones a sus subordinados sobre cómo debían actuar con relación a la organización de las elecciones en sus localidades. Sin embargo, ante la «atmosfera de comentarios» sobre dichos comicios que se había desatado en el interior de la organización, el jefe provincial se veía obligado a «refrescar la memoria de todos, para así poder comprender mejor el alcance de las elecciones».

De este modo, que FET-JONS aceptase no solo que se celebrasen elecciones, sino intervenir en ellas de manera activa no suponía que las «viejas consignas» del partido hubiesen "perdido actualidad». Por el contrario, esa decisión debía de situarse en el contexto de la capacidad del Movimiento de adaptarse a las situaciones que más convenían a «los intereses de España». En este sentido, Manual García del Olmo subrayaba que «el hecho de que hoy, frente a un mundo deshecho, nuestra patria se mantenga unida y en orden» era la mejor prueba de que «la flexibilidad que el Movimiento ha sabido imponer a su conducta ha servido para salvar a España de los terribles temporales desatados con motivo de la contienda universal». Como consecuencia de todo ello, la posición del partido sobre los futuros comicios debía interpretarse bajo los siguientes parámetros:

«Hubo un tiempo en que a la Falange se pidió el ímpetu, el arma y la sangre. Porque a la guerra declarada por nuestros enemigos no cabía oponer otro argumento que el de la guerra. Hoy se le pide que continúe la batalla en otro terreno. Esta segunda batalla hay que ganarla también. Ante las elecciones anunciadas esta jefatura tiene que adoptar una postura política e inteligente. Por dormido que esté el espíritu de los afiliados, esa jefatura no puede desmayar ante la necesidad inexcusable de despertarlo haciéndoles comprender que

23 La información personal sobre Manuel García del Olmo en «Datos biográficos», ABC de Madrid, 4-10-1945, p. 10. 
si bien no se va a ventilar en estas elecciones como en las famosas del 12 de abril la suerte de Espańa, hay que aprovechar esta coyuntura para afianzar las posiciones obtenidas en las trincheras ${ }^{24} \%$.

Con estas palabras, como más tarde le contaba al vicesecretario general del Movimiento, Manuel García trataba de «transmitir al falangista la preocupación de que su presencia en las elecciones era necesaria», así como que fuese cual fuese su opinión sobre el sufragio, este era «un instrumento que ha de utilizar para la consolidación del Movimiento con la misma decisión y agilidad con que antes utilizó el fusil para su implantación». Además, las elecciones constituirían una excepcional herramienta para "descubrir las cartas del enemigo» ya que, según él, si «Falange se preocupa honradamente de hacer sus preparativos para entrar en la liza», los "adversarios» que pretendiesen utilizar las elecciones con fines políticos se verían obligados a "mover más descaradamente sus hilos» por lo que resultaría mucho más fácil para el partido «su localización y el descubrimiento de los propósitos que les animan ${ }^{25}$.

\section{EL CONTROL DE LAS JUNTAS PROVINCIALES DEL CENSO}

El primer paso de la Organización Sindical para poder desarrollar la tarea que le había sido encomendada fue lograr la representación necesaria en las juntas provinciales y municipales del censo electoral. De acuerdo con lo establecido por el Decreto de 29 de septiembre de 1945, estos dos organismos eran una pieza clave del proceso de preparación de las elecciones municipales por el tercio de representación familiar. Ello se debía a que eran los encargados de aceptar o rechazar las reclamaciones que se pudieran presentar sobre las listas preliminares del censo que serían elaboradas por las jefaturas provinciales de estadística ${ }^{26}$.

En este sentido, la clave de su estrategia estuvo precisamente en el citado Decreto de 29 de septiembre de 1945, que fijó las normas para la formación del censo. En su artículo segundo, el decreto establecía que los diez vocales que el artículo once de la Ley Electoral de 1907 reservaba en cada junta provincial del censo a los presidentes de las sociedades económicas, cámaras

24 Las cursivas son nuestras. Circular reservada 19-945 del jefe provincial del Movimiento de Málaga a los jefes locales de la provincia. 27 de octubre de 1945. AGA (9) $51 / 18447$.

25 Informe enviado por el jefe provincial del Movimiento de Málaga al vicesecretario general del Movimiento el 3 de noviembre de 1945. AGA (9) 51/18984.

26 Véase los artículos 9, 10, 11, 12 y 13 del Decreto de 29 de septiembre de 1945. 
agrarias y de comercio, hermandades o asociaciones agrícolas, industriales, económicas o culturales, serían sustituidos por los presidentes de las distintas delegaciones sindicales de la Organización Sindical Española en cada provincia. Un cambio que resultaba congruente con lo establecido por la Ley de Unidad Sindical de 26 de enero de 1940, según la cual la Organización Sindical era la única reconocida por el Estado para hacer llegar hasta él las aspiraciones de los productores de la nación, por lo que aquellas asociaciones creadas para defender o representar total o parcialmente intereses económicos o de clase, debían incorporarse a ella ${ }^{27}$.

Sorprendentemente, el Decreto de 29 de septiembre de 1945 no estableció ningún mecanismo que permitiese una intervención similar de los organismos sindicales en las juntas municipales del censo. Como consecuencia, Falange encontró mayores dificultades para colocar a sus representantes en dichas juntas ${ }^{28}$. A pesar de que no podemos profundizar en el proceso de ocupación de las juntas municipales por parte de Falange porque carecemos de la documentación relativa a este asunto, creemos que el partido pudo sortear fácilmente este obstáculo gracias al control efectivo que logró de las juntas provinciales, que podían corregir las decisiones de las juntas municipales.

De este modo, mediante su orden de servicio número 53, de 13 de octubre de 1945, la Vicesecretaría General de Ordenación Social fijó tanto el procedimiento para seleccionar a los integrantes del partido que serían propuestos para formar parte de las comisiones provinciales del censo electoral, como los pasos a seguir para lograr que aquellos fueron finalmente nombrados miembros de dichas comisiones ${ }^{29}$. De acuerdo con dicha orden, los delegados provinciales de sindicatos o, en su defecto, los vicesecretarios provinciales de Ordenación Social, eran los responsables de elegir los nombres de esas personas. Para ello debían confeccionar una lista formada por el delegado provincial de Sindicatos, que la encabezaría; los vicesecretarios provinciales de Ordenación Social y Ordenación Económica; el jefe provincial de la Obra Sindical Educación y Descanso, y todos los jefes de los sindicatos, gremios y hermandades provinciales.

Artículos 1 y 2 de la Ley de Unidad Sindical de 26 de enero de 1940, BOE, núm. 31, 31-1-1940, pp. 772-773.

28 Así se desprende de los informes enviados al vicesecretario general del Movimiento por Manuel García del Olmo, el 13 de noviembre de 1945, AGA (9) 5118447 y por José María de Olazábal al vicesecretario general del Movimiento, el 15 de noviembre de 1945. AGA (9) 51/18984.

29 La orden de servicio núm. 53 de la Vicesecretaría General de Ordenación Social de 13 de octubre de 1945 puede encontrarse en AGA (9) 51/18984. 
Posteriormente, debían enviar esa lista a los gobernadores civiles, que eran los encargados de confeccionar la lista final y enviarla al presidente de la correspondiente junta provincial del censo. Para redactar dicha lista, el gobernador civil debía incluir en ella a los cuatro representantes de los organismos sindicales que encabezan la lista que había recibido y seleccionar, de entre los restantes componentes de esa misma lista, seis representantes más en atención a la importancia económico social en la provincia de la entidad sindical a la que pertenecían o a las especiales circunstancias que concurriesen en ellas. Además, al enviar la citada lista final a los presidentes de las juntas provinciales del censo los gobernadores civiles debían solicitar a los mismos que otorgaran a la Organización Sindical las diez vocalías de la junta.

Una vez confeccionada y enviada la lista final, los delegados provinciales de sindicatos, o en su defecto los vicesecretarios provinciales de ordenación social, debían ponerse en contacto con el presidente de su correspondiente junta provincial del censo para informarse de la composición final de la misma. En este sentido, si el partido no obtenía todos los puestos que había solicitado o no se incluía entre los miembros de la junta a todas las personas de su lista, el gobernador civil o los delegados provinciales de sindicatos o los vicesecretarios provinciales de Ordenación Social debían recurrir a la Junta Central del Censo Electoral la designación efectuada. Finalmente, el encargado de realizar la apelación debía dar cuenta de la misma al delegado nacional de Sindicatos para que este pudiese «interesarse por la pronta resolución de los recursos».

El plan diseñado por FET-JONS consiguió un gran éxito, ya que muchos presidentes de juntas provinciales del censo accedieron a sus peticiones en primera instancia. Así, en Burgos, Córdoba, Lugo o Salamanca el partido logró acaparar los diez vocales de la junta; en Albacete, Huesca, Ávila o Valladolid consiguió nueve de las diez vocalías, y en Alicante o Tarragona pudo colocar a ocho de sus representantes. Sin embargo, su nivel de exigencia fue tan alto que no solo recurrió de inmediato las decisiones de las juntas provinciales de los censos de Badajoz, que le había concedido seis puestos; Barcelona, Castellón o Cuenca, que le otorgaron cinco puestos, o Pontevedra o Gerona, que le concedieron 4 puestos, sino que también interpuso recursos contra las decisiones de las juntas de Álava u Orense, que le habían otorgado ocho puestos ${ }^{30}$.

30 La información que utilizamos en este párrafo procede de un informe de la Delegación Nacional de Sindicatos, fechado el 5 de noviembre de 1945, donde se relacionan los nombres de los representantes de dicha delegación que han sido designados en cada junta provincial del censo electoral. AGA (9) 51/18984. 
El caso de Orense es particularmente revelador de este exceso de celo del partido por lograr acaparar todos los puestos posibles en las juntas provinciales del censo. Según la versión del delegado provincial de Sindicatos, el 9 de octubre de 1945 el presidente de la Audiencia, que era por ley el presidente de la Junta Provincial del Censo, le telefoneó para pedirle que le enviase los nombres de los jefes de ocho sindicatos de la provincia para que al día siguiente tomasen posesión como miembros de la Junta Provincial del Censo. El delegado provincial accedió de inmediato y le envió una lista con los nombres de las ocho personas que al día siguiente fueron nombradas vocales de la junta.

Siete días después, el 17 de octubre, se recibió en la Delegación Provincial de Sindicatos la orden número 53 de la Vicesecretaría General de Ordenación Social que establecía que debían corresponder a esa delegación los diez puestos de vocales de las citadas juntas. Así, atendiendo a las instrucciones superiores, el delegado provincial de Sindicatos de Orense fue a visitar al secretario de la Junta Provincial del Censo Electoral para exponerle el caso, aunque aquel se negó a retirar los dos puestos restantes que habían sido concedidos a entidades culturales y mercantiles de la provincia para entregárselos también a la Organización Sindical. Ante esta decisión, el delegado provincial formuló la consiguiente reclamación ante la Junta Central del Censo, cuya resolución final desconocemos ${ }^{31}$.

El caso más extremo fue posiblemente el de La Coruña, donde la Junta Provincial del Censo no concedió ni un solo puesto al partido único. Una situación que llevó al jefe provincial accidental del Movimiento, Miguel Rayero Gijón, a organizar diversas reuniones, entre ellas una a la que asistieron el subjefe provincial del Movimiento, el delegado sindical, el magistrado de Trabajo, el jefe de Estadística y el secretario de la Diputación. Sin embargo, ninguna de ellas hizo cambiar de opinión al presidente de la Junta Provincial del Censo, quien consideraba que la decisión de la junta se ajustaba a lo estipulado por la ley. Por lo tanto, el día 2 de octubre el gobernador civil de La Coruña envío al secretario de las Cortes, que actuaba por ley como secretario de la Junta Central del Censo, el recurso de anulación de la Junta Provincial del Censo de La Coruña ${ }^{32}$.

Como ya hemos comentado anteriormente, las reclamaciones de las delegaciones provinciales de sindicatos ante la Junta Central del Censo fueron acompañadas de las cartas que el vicesecretario nacional de Ordenación Social

31 La información sobre este asunto en el informe redacto por el delegado provincial de Sindicatos de Orense el 9 de noviembre de 1945. AGA (9) 51/18984.

32 Informe del jefe provincial del Movimiento de La Coruña de 31 de octubre de 1945. AGA (9) 51/18447. 
envió a la misma para, según se explicaba en la orden de servicio número 53, «interesar la pronta resolución de los recursos». Sin embargo, el tono que José María de Olazábal empleó en la redacción de dichas cartas, algunas de las cuales hemos podido consultar, tuvo un carácter bastante intimidatorio. El mejor ejemplo de los que disponemos es, sin duda, la carta que la citada autoridad envió a la Junta Central del Censo en relación con la reclamación presentada ante la misma por la Delegación Provincial de Sindicatos de La Coruña, a la que acabamos de aludir.

La citada misiva se dividía en tres partes en las que el vicesecretario general de Ordenación Social presentaba a la Junta Central del Censo los motivos de la misiva, les acusaba de hacer vieja política y, finalmente, mencionaba la legislación que, según él, no había sido tenida en cuenta al configurar la composición de la Junta Provincial del Censo de La Coruña. Así, en la primera parte de la carta, Olazábal mostraba su "profundo asombro» ante la decisión de la mencionada junta provincial de no conceder a la «organización sindical de aquella capital el derecho a ostentar en el organismo provincial electoral la representación de la que es acreedora».

A continuación, el vicesecretario de la organización sindical lanzaba contra los miembros de la Junta Provincial del Censo una de las acusaciones más utilizadas por los falangistas contra sus adversarios en aquellos tiempos. Según sus propias palabras, si la decisión de esa junta provincial no emanara «de un organismo cuyos componentes, ostentan cargos representativos de actividades culturales y profesionales del más alto rango", podría pensarse que "nos hallamos ante una maniobra de difusa finalidad, remedo de antiguas situaciones electorales». Es decir, les acusaba de practicar «vieja política», y eso era algo que, en su opinión, no podía «tener cabida en el nuevo sistema de sufragio» ni tampoco «en la tónica que desde el poder quiere darse y se está dando a las elecciones que se avecinan".

Por último, en su intento por «robustecer y ampliar los fundamentos del recurso presentado por la Delegación Provincial de Sindicatos de La Coruña», Olazábal afirmaba que la Junta Provincial del Censo de La Coruña había realizado una «errónea interpretación» del decreto de 29 de Septiembre de 1945. Así, bajo su punto de vista, la decisión del citado organismo provincial era completamente «anómala» puesto que suponía aceptar que la Organización Sindical no tenía existencia «ni legal ni real», lo cual se oponía abiertamente a la legislación vigente. En este sentido, el dirigente sindical subrayaba que tanto el artículo segundo del citado decreto como la Ley de Unidad Sindical, también comentada anteriormente, avalaban el derecho de la Organización Sindical a estar representada en las juntas provinciales del censo, algo que «parecen desconocer los cultos componentes de la Junta Provincial del Censo 
Electoral de La Coruña». Por todo ello, pedía a la Junta Central que anulara la decisión de la Junta Provincial de La Coruña y le concediese los diez puestos solicitados ${ }^{33}$.

Desgraciadamente no disponemos de información que nos permita conocer cuál fue el resultado de todas las reclamaciones que se presentaron ante la Junta Central del Censo Electoral y, por tanto, el balance final de la estrategia diseñada por FET para tener presencia formal en los organismos encargados de organizar las elecciones. Sin embargo, en uno de los informes anteriormente mencionados, José María de Olazábal afirmaba que los resultados obtenidos por el partido en relación con este asunto «habían respondido plenamente a los propósitos perseguidos» lo que, en su opinión se debía a que dicha estrategia había «sorprendiendo en casi todas partes a los presidentes de las Juntas que han adjudicado en la mayoría de los casos una amplia representación a la organización sindical».

No obstante, continuaba el vicesecretario nacional de Ordenación Social, la ambiciosa interpretación del Decreto de 29 de septiembre de 1945 hecha por el partido, que le llevó a reclamar la totalidad de los diez puestos de vocales de cada junta provincial del censo electoral, había dado lugar a un elevado número de recursos que, a pesar de haber sido fallados en el sentido de ampliar la representación concedida inicialmente al mismo en las citadas juntas provinciales, no le habían permitido copar la totalidad de dichos puestos.

Por ello, Olazábal dejó la puerta abierta a la posibilidad de solicitar el aplazamiento de las elecciones. A su entender, la interpretación legalista que se había dado en algunas provincias a los preceptos del decreto mencionado relacionados con los de la Ley de 1907 había dado lugar «a nuestra exclusión de algunas juntas ${ }^{34}$. Estos hechos, junto con la resolución que se había dado por

33 La carta de José María de Olazábal a la Junta Central del Censo Electoral en AGA (9) 51/18984. En un tono similar estaba redacta la carta que Olazábal envió a la citada Junta Central en relación a la reclamación presentada por la Delegación Provincial de Sindicatos de Navarra con referencia al mismo asunto. Véase AGA (9) 51/18984.

34 Una de las provincias donde FET no había podido conseguir todos los puestos que deseaba en la junta provincial del censo como consecuencia de la citada interpretación legalista fue Palencia. Allí, la Junta Central del Censo Electoral había fallado en contra del partido, que reclamaba muchos más puestos de los que le fueron concedidos, basándose en el argumento de que el punto 4 del artículo 11 de la Ley Electoral de 1907 establecía que varios de los puestos de vocales de las juntas del censo debían ser ocupados por representantes de aquellos gremios relacionados con el pago de la contribución industrial, gremios que según la Junta Central del Censo todavía existían y eran ajenos a la organización sindical. Véase al respecto la resolución de la Junta Central del Censo de 29 de octubre de 1945 en AGA (9) 51/18447. 
la Junta Central del Censo a algunas de las reclamaciones que se habían presentado ante ella, podían servir de base para que las juntas electivas sindicales plantearan una «seria y documentada petición de aplazamiento de la convocatoria electoral» basándose en la idea de que dichas eliminaciones significaban un «atropello para la defensa de sus intereses»" ${ }^{35}$.

\section{LA DEPURACIÓN DE LOS CENSOS ELECTORALES}

Tras haber colocado a sus representantes en todas las juntas provinciales y municipales del censo, el siguiente paso del partido en su estrategia para garantizar el control de los futuros comicios fue la depuración del censo electoral. A pesar de que la documentación sobre esta etapa del proceso es muy escasa, hemos podido reconstruir los principales aspectos de la misma gracias a la correspondencia que mantuvieron el jefe provincial del Movimiento de Málaga y el vicesecretario general del Movimiento entre octubre y noviembre de 1945, y que se conserva en el Archivo General de la Administración.

En su circular 175 de octubre de 1945, la Secretaría General del Movimiento informó a los jefes provinciales del Movimiento sobre «la importancia trascendental» del censo electoral y la necesidad de que el mismo se ajustase «a la realidad y refleje sin filtraciones de elementos que carezcan de este derecho [el de sufragio activo] y que puedan desvirtuar la pureza de la ley [electoral de 1907]». En este sentido, la circular le atribuía al partido la función de "velar por la pureza del sufragio» y para lograrlo señalaba a los jefes provinciales la importancia de los artículos 5 y 6 del decreto de 29 de septiembre por el que se establecían las instrucciones para la formación del censo electoral. El primero de ellos establecía los requisitos para poder ser cabeza de familia y, por tanto, tener derecho a voto. El segundo, que la circular consideraba de «extraordinario interés», fijaba las condiciones para poder excluir a los vecinos que en principio ostentaran la condición de cabezas de familia ${ }^{36}$.

35 El citado informe de Olazábal, que fue redactado el 14 de noviembre de 1945, puede localizarse en AGA (9) 51/18984.

36 En este sentido, no podían figurar en el censo electoral de cabezas de familia las siguientes personas: a) quienes hubiesen sido condenados por sentencia firme a penas que excedan de un mes y un día; b) los condenados a penas leves que no hubiesen acreditado el cumplimiento de la sentencia, y c) los acogidos a establecimientos benéficos o pobres de solemnidad. Un conjunto de criterios que podía aplicarse perfectamente a los republicanos represaliados. 
No obstante, la citada circular hacía especial hincapié en las circunstancias que permitían la exclusión de todos «los delincuentes enemigos de la Patria y de los principios del Movimiento». Además, en aquellos casos en los que los considerados por el partido como enemigos del régimen no hubieran podido ser eliminados del censo, el texto ordenaba a los jefes locales del Movimiento presentar reclamaciones ante las juntas locales del censo ${ }^{37}$, cuando estas realizaran su reunión oficial. Asimismo, si dichos organismos tampoco satisfacían esas demandas, los representantes del partido en las juntas provinciales del censo debían exigir su cumplimiento. Finalmente, en caso de ser necesario, la Secretaría General del Movimiento no dudaba en recomendar a sus mandos provinciales solicitar amparo ante la correspondiente Audiencia Provincial, para lo cual debían contar con la ayuda del jefe de Justicia y Derecho de la respectiva jefatura provincial ${ }^{38}$.

No obstante, la depuración del censo electoral no fue únicamente responsabilidad de las autoridades provinciales y locales de FET-JONS, los afiliados también debían participar. Así se desprende de la carta que la Jefatura Provincial del Movimiento de Málaga envió a todos los afiliados de la provincia. En ella, el jefe provincial, ante «el carácter directo de la elección» exhortaba a los militantes a contribuir a la correcta selección de los cabezas de familia que debían de figurar en el censo. En este sentido, la autoridad provincial les recordaba que el hecho de que nadie fuese a ser elegido en virtud de sus «ideas políticas» no justificaba su «despreocupación ante los próximos comicios». De este modo, si como vecinos de un municipio debían estar interesados en que sus representantes «reúnan las mejores condiciones de actitud y probidad para el desempeño de su cometido», como militantes de la Falange debían de estarlo también en que «a través del instrumento electoral no se filtre la mano de los eternos enemigos de España».

Como consecuencia, todos los militantes tenían que contribuir a excluir del censo a todos «aquellos que no deban figurar» por haber sido «condenados por sentencia firme a penas que excedan de un mes y un día». Para ello, debían

37 En la Circular reservada 19-945 del jefe provincial del Movimiento de Málaga se afirma que, si bien los jefes locales no formaban parte de las juntas municipales del censo, en ellas siempre había, al menos, un gestor falangista, sometido a la disciplina del jefe local, que debía velar "con especial cuidado» por las resoluciones adoptadas por dichas juntas, «especialmente respecto a las reclamaciones de su jefe», para lo cual ambos debían mantener un estrecho contacto. En este sentido, cualquier diferencia entre el gestor y la jefatura local correspondiente debía ser comunicada urgentemente a la jefatura provincial. AGA (9) 51/18447.

38 Circular 175 de la Secretaria General del Movimiento. Octubre de 1945. AGA (9) $51 / 18984$. 
examinar las listas preliminares del censo durante su periodo de exposición pública e informar a la secretaría local del Movimiento acerca de «las irregularidades que hayas tenido ocasión de observar sobre la inclusión indebida de condenados o de individuos que no sean cabezas de familia, así como de cualquier duda que te surja, para que se entable la correspondiente reclamación $" 39$.

Con todo, el proceso de depuración del censo no solo perseguía excluir del mismo a la mayor cantidad posible de personas no afines al régimen. Además, pretendía incluir en el mismo a tantos adeptos como fuese posible. En este sentido, Manuel García del Olmo se lo expuso con total claridad a los jefes locales del Movimiento de la provincia de Málaga, «ningún afiliado a la Falange, cabeza de familia, puede quedar excluido del censo» ${ }^{40}$. Tarea que, al igual que la exclusión, debían de realizar tanto las jefaturas locales de FET-JONS como los propios afiliados. Las primeras no solo tenían que comparar las listas preliminares del censo con la lista de afiliados de su jefatura, sino que también eran responsables de garantizar que figurasen en dicho censo aquellos que sin estar inscritos en el Movimiento mostraran una adhesión de la que no se podía dudar $^{41}$. Por su parte, los afiliados, en el caso de que fuesen cabezas de familia, debían comprobar que estaban incluidos en el censo. Si no lo eran, debían transmitir dicha preocupación a los militantes que lo fuesen o «a aquellos otros que no siendo militantes estén colocados dentro de la línea ideológica del Movimiento o tengan una inquebrantable adhesión al mismo» ${ }^{42}$.

Finalmente, de manera paralela a las actividades realizadas por las jefaturas locales y por los afiliados, el jefe provincial del Movimiento de Málaga llevó acabo diferentes actividades relacionadas con el proceso de depuración del censo electoral. En primer lugar, se reunió con los inspectores comarcales de FET-JONS, los jefes locales y los alcaldes de los pueblos que eran cabeza de partido judicial a los que transmitió instrucciones y aclaró cuantas preguntas le hicieron en relación con la exclusión e inclusión de cabezas de familia en el censo ${ }^{43}$. Asimismo,

39 Carta enviada por el jefe provincial del Movimiento de Málaga a los afiliados de la provincia el 31 de octubre de 1945. AGA (9) 51/18984.

40 Circular reservada 19-945 del jefe provincial del Movimiento de Málaga a los jefes locales de la provincia. 27 de octubre de 1945. AGA (9) 51/18447.

41 Circular reservada 19-945 del jefe provincial del Movimiento de Málaga a los jefes locales de la provincia. 27 de octubre de 1945. AGA (9) 51/18447.

42 Carta enviada por el jefe provincial del Movimiento de Málaga a los afiliados de la provincia el 31 de octubre de 1945. AGA (9) 51/18984.

43 Las instrucciones que les transmitió se encuentran resumidas en el documento «Extracto de la misión encomendada a los jefes locales del Movimiento, con motivo de la confección del censo electoral de cabezas de familia». AGA (9) 51/18984 
mantuvo una reunión con el jefe de Servicios de Estadística para acordar la forma en la que las diferentes secretarias locales del partido en la provincia consultarían las listas preliminares del censo. Por otro lado, ordenó a la Secretaría Local del Movimiento de la Ciudad de Málaga realizar un estudio del número de afiliados de FET-JONS que había en cada calle de todas y cada una de las secciones electorales de la ciudad.

Por último, en su afán por llevar al máximo la depuración del censo, el jefe provincial escribió al gobernador militar solicitándole información de aquellos individuos que habiendo sido condenados por tribunales militares se encontraran en libertad no sometida a vigilancia y, por tanto, no apareciesen en los registros que debían enviar a las juntas provinciales del censo las juntas provinciales de libertad vigilada ${ }^{44}$. La idea debió de parecerle interesante al vicesecretario general del Movimiento, puesto que solicitó información a la propia Subdirección General de Libertad Vigilada sobre la aplicación general de esta medida a todo el territorio nacional. Sin embargo, la respuesta de la citada subdirección fue contundente: «Puede tener VE la seguridad —escribió el Subdirector General — de que los condenados procedentes de la rebelión marxista [...] favorecidos con un indulto total [...] son un número prácticamente muy escaso» que no justificaba «la ingente tarea necesaria para aclarar debidamente su situación y la residencia que tienen en la actualidad $»^{45}$

La escasez de documentación nos impide conocer cuál fue el resultado de estas activas políticas de depuración del censo electoral puestas en marcha por FET-JONS. Sin embargo, sí disponemos de algunas pequeñas referencias al respecto para el caso de Málaga. Por lo que se refiere a las exclusiones, Manuel García del Olmo informó a Rodrigo Vivar Téllez de que «la amplitud de la capital y la carencia de documentación necesaria» no habían permitido "hacer un gran número de exclusiones», al contrario de lo que sucedió en la provincia donde las mismas habían sido numerosas. En relación con las inclusiones, el jefe provincial afirmaba que su jefatura había logrado la inclusión de muchas personas en la provincia y "de cerca de un millar de camaradas y personas cuya adhesión al Movimiento no es dudosa» en el censo de la capital ${ }^{46}$.

44 La información sobre las actividades paralelas realizadas por el jefe provincial del Movimiento de Málaga en el informe que este le remitió al vicesecretario general del Movimiento el 3 de noviembre de 1945. AGA (9) 18984.

45 Respuesta del subdelegado general de Libertad Vigilada enviada al vicesecretario general del Movimiento el 6 de diciembre de 1945. AGA (9) 51/18984.

46 Carta enviada por el jefe provincial del Movimiento al vicesecretario general del Movimiento el 13 de noviembre de 1945. AGA (9) 51/18447. 
No obstante, el notario sevillano no ocultó a su superior algunas quejas relevantes sobre el citado proceso. Por un lado, informaba de que no habían podido hacerse más inclusiones porque mientras muchos miembros del partido no se habían empadronado en la ciudad "por desidia», los miembros de la clase obrera, que si estaban empadronados por necesitar dicho certificado para inscribirse en las oficinas de colocación, habían solicitado su inclusión en un número muy bajo ${ }^{47}$. En este sentido, en una carta enviada por el líder provincial a su superior unos días más tarde, el primero informaba al segundo de que "en la mayoría de la provincia» los vecinos habían «acogido con frialdad» la orden de examinar las listas del censo electoral. De hecho, subrayaba, «nadie se ha preocupado lo más mínimo, a excepción de los jefes locales, de ver si figuraban o no incluidos en el censo» ${ }^{48}$.

\section{EL CONTROL DE LAS CANDIDATURAS. LAS DIFERENCIAS ENTRE EL PARTIDO Y LA ORGANIZACIÓN SINDICAL}

La última fase del proceso de organización de aquellas elecciones municipales previstas para marzo de 1946 era la destinada a la selección de los candidatos que se presentarían finalmente a la elección. A pesar de que esta etapa no llegó a ponerse en marcha, la Organización Sindical desarrolló un plan para su control efectivo que, sin embargo, fue rechazado de plano por el vicesecretario general del Movimiento. Al parecer, el plan de la Organización Sindical fue diseñado por José María de Olazábal, quien envió un informe dando cuenta del mismo tanto al delegado nacional de Sindicatos como al vicesecretario general del Movimiento el 15 de noviembre de 1945. No obstante, dos días después fue el delegado nacional de Sindicatos, Fermín Sanz Orrio, quien escribió a Rodrigo Vivar Téllez para darle cuenta del mismo plan, pero adjudicándose él la autoría ${ }^{49}$.

En ambos informes se mencionaban diversas razones por las que, según el criterio de sus autores, era necesaria la intervención de la Organización Sindical en el proceso de selección de candidatos. En primer lugar, Fermín Sanz Orrio afirmaba que las actividades llevadas a cabo por dicha organización

47 Carta enviada por el jefe provincial del Movimiento en Málaga al vicesecretario general del Movimiento el 13 de noviembre de 1945. AGA (9) 51/18447.

48 Carta enviada por el jefe provincial del Movimiento en Málaga al vicesecretario general del Movimiento el 30 de noviembre de 1945. AGA (9) 51/18447.

49 Ambos informes, así como la opinión al respecto de dicho plan del vicesecretario general del Movimiento pueden encontrarse en AGA (9) 51/18984. 
para lograr el control de las juntas provinciales y municipales del censo habían puesto de manifiesto algo inquietante. La presencia en la sociedad española de "ciertos elementos», que en muchas ocasiones incluso hacían "gala de sus sentimientos antifalangistas», que habían intentado evitar la intervención de la citada organización.

En segundo lugar, el delegado nacional de Sindicatos se mostraba preocupado porque los estudios del censo electoral realizados por la Vicesecretaría Nacional de Ordenación Social mostraban la presencia en el mismo de «grupos de cabezas de familia de distinta significación política que tal vez entren en juego en la contienda electoral». En este sentido, Fermín Sanz Orrio informaba de que aparte de las personas indiscutiblemente afectas al Movimiento, había en los censos dos tipos de enemigos. Por un lado, se encontraban aquellos que habiendo sido inicialmente leales al régimen, «en la molicie de la paz y la tranquilidad, de sus compromisos y deberes», habían dejado de serlo y «por frivolidad, resentimiento o desencanto en el logro de ambiciones, están dispuestos a atacarnos». Por otro lado, estaban los «rojos declarados» a quienes, por falta material de tiempo, no se había podido excluir del censo.

De hecho, el líder de la Delegación Nacional de Sindicatos iba más allá y afirmaba que la actividad de estos electores podía tener «efectos políticos» puesto que podían «apoyar candidaturas adversas» o provocar altos porcentajes de abstención. En este sentido, el vicesecretario nacional de Ordenación Social era mucho más preciso en su informe. Bajo su punto de vista, «los elementos de significación marxista» no excluidos del censo electoral se abstendrían de presentar candidaturas con el objetivo de evitar que el voto «se polarice por reacción en una candidatura afecta al Movimiento». De este modo, siempre según José María de Olazábal, si se presentaran solamente candidaturas afectas al Movimiento, estos opositores optarían por la abstención a fin de boicotear la elección. Por el contrario, estaba convencido de que en el caso de que se presentase alguna candidatura integrada por personas antimarxistas pero hostiles al Movimiento, aquellos individuos la apoyarían con sus votos.

En tercer lugar, el delegado nacional de Sindicatos señalaba que en muchos casos la composición de las juntas provinciales y municipales del censo tenía un carácter excesivamente "conservador en lo económico", habiendo quedado excluidas de las mismas las «clases trabajadoras». En este sentido, Fermín Sanz Orrio afirmaba que el «rigor de la depuración» afectaba siempre mucho más a las "clases humildes que a las poderosas», puesto que estas últimas, aun siendo "más peligrosas si cabe que muchos marxistas», lograban «evadir la acción de la justicia». De este modo, el abogado navarro entendía que solo mediante la participación en las elecciones de la Organización Sindical, «con 
su composición netamente popular», se podía equilibrar la situación de desventaja en la que se encontraban los trabajadores.

Finalmente, Fermín Sanz Orrio ponía de manifiesto que la actuación directa de la Falange en las elecciones «resultaría muy inconveniente». Las razones que se escondían tras esa afirmación las había puesto de manifiesto en su informe José María de Olazábal. Para el vicesecretario general de Ordenación Social existían varios motivos de peso para evitar dicha intervención. En primer lugar, porque la formación de una candidatura por parte del partido "contribuiría a dar a la elección el sentido político que se quiere evitar». En segundo lugar, porque con ello se "haría el juego» a todos aquellos que trataban de instaurar la "pugna política» dentro del régimen, "facilitándoles el reverso que falta a su medalla». Finalmente, porque muy posiblemente esa candidatura "solo contaría con el apoyo de los militantes del Partido». En este sentido, Olazábal consideraba que tras el examen al que habían sido sometidos los censos electorales no parecía que el porcentaje de afiliados a FET-JONS con respecto al total de los censados aconsejase «luchar con solo esa fuerza frente a otras candidaturas», sobre todo teniendo en cuenta que no era posible averiguar «el grado de sincera adhesión y disciplina de todos cuantos aparecen como tales [afiliados]».

Todo esto llevaba a Fermín Sanz Orrio a concluir que el único medio para conseguir que las elecciones que se avecinaban tuviesen "calor popular" y a la vez evitar «una maniobra política de los enemigos del Régimen» era que la Organización Sindical pudiese «actuar intensamente no ya en el tercio que le corresponde, sino en la formación de candidaturas y su votación por los cabezas de familia». Sin embargo, él mismo reconocía que esa «labor no puede ser adoptada por nuestra Organización por iniciativa propia» sino que debía ser «previamente autorizada por la Superioridad» y además contar con «el acuerdo de la mayoría de los representantes sindicales, bajo el compromiso de que las fuerzas sociales serán, gracias a ello, debidamente atendidas en la composición de los ayuntamientos».

Como puede comprobarse, las clases populares tenían una presencia relevante en el discurso de la Delegación Nacional de Sindicatos sobre su estrategia para intervenir en la organización de las elecciones municipales de representación familiar. Muy posiblemente, ese hecho respondía a uno de los objetivos que pretendía conseguir la Organización al realizar esa labor. El delegado nacional de Sindicatos se lo confesó abiertamente al vicesecretario general del Movimiento en el informe al que nos estamos refiriendo: «No he de ocultarte a ti - le dijo- que la organización desea vivamente eliminar en las elecciones próximas enemigos a la izquierda del régimen». Para ello, el plan era que fuese la propia Organización Sindical la que levantese «la bandera de 
la inquietud económico-social de las gentes humildes». De este modo, proseguía Fermín Sanz Orrio, sería posible desbaratar tanto «las maniobras de los partidos marxistas» como «las añagazas de esas gentes que debieran ser conservadoras y por rencor o por estupidez se han colocado en actitud hostil, dispuestas a asociarse con sus propios verdugos por satisfacer aquellas malas pasiones».

Así, según el informe del delegado nacional de Sindicatos el plan para lograr el control de las candidaturas que se presentaran a las futuras elecciones era el siguiente. Se trataba de organizar candidaturas sindicales dentro de las cuales estuviesen representados los siguientes tres tipos de cabezas de familia. Primero, "gentes de posición económica solvente», o dicho de otro modo, empresarios reputados en sus respectivas localidades que pudiesen velar en los ayuntamientos "por los justos intereses de los que contribuyen a sostener el erario municipal». Segundo, «jerarquías sindicales» expertas en todo lo relativo a la administración local, que sin ser «ni demagogos ni explotadores del obrero» se caracterizasen por «su sensatez y cordura en los problemas sociales». Finalmente, deberían estar representados los obreros de mayor prestigio en sus localidades. Sin embargo, estos se subdividirían en dos grupos. Por un lado, "fervorosos falangistas», excombatientes, camisas viejas, etc. Por otro, obreros de izquierdas «pero sanos y a los que puede otorgarse un margen de confianza». Con respecto a estos últimos, la idea era que la mayoría serían finalmente conquistados por el régimen y el resto podría realizar una oposición «incluso conveniente».

En definitiva, sentenciaba Fermín Sanz Orrio, el plan podría «asustar a los pusilánimes» pero no «a quien tenga de la política un profundo concepto». En este sentido, José María de Olazábal indicaba en su informe que esta forma de organizar las candidaturas de la Organización Sindical garantizaba que las mismas serían mayoritariamente apoyadas por los votantes. Así, en su opinión, las mismas obtendrían el apoyo de tres sectores fundamentales. Por un lado, los empresarios vinculados a la Organización Sindical, con su enorme influencia en la población. Por otro, la gran mayoría de los trabajadores que, según el criterio del vicesecretario general de Ordenación Social, no encontrarían en otras candidaturas las posibilidades de representación de sus intereses que les ofrecerían las de la Organización Sindical. Finalmente, los «marxistas», quienes, también en opinión de la citada autoridad, "preferirán apoyarla y obtener algunos puestos encubiertamente, que robustecer otras candidaturas de sentido y orientación burguesa». Además, en caso de que estos sectores recibiesen instrucciones para abstenerse «no podrían hacer frente a la desorientación que ha de suponerles el ver nombres por ellos conocidos en nuestra candidatura». 
A pesar de las garantías de éxito que ambos dirigentes sindicales auguraban a su plan, el vicesecretario general del Movimiento tenía una opinión al respecto muy diferente, tal y como se deduce de la durísima evaluación que hizo del mismo, del que llegó a afirmar que solo merecía su «repulsa». Las críticas de Rodrigo Vivar Téllez a las pretensiones de Fermín Sanz Orrio y José María de Olazábal pueden resumirse en dos puntos. En primer lugar, el vicesecretario general del Movimiento consideraba un gran error la idea de que el Movimiento no presentase candidaturas propias a las elecciones. Bajo su punto de vista, esa decisión supondría ceder sin oposición las concejalías de representación familiar a los «enemigos o por lo menos a los que no están integrados en el Movimiento y se desentienden de él». De este modo, aunque compartía la idea de que Falange, como "organización política» que era, no podía presentar candidatos directamente, consideraba totalmente improcedente que «el Movimiento se ponga al margen de las elecciones y de su proclamación de candidatos, inhibiéndose en un problema de tan extraordinaria importancia política». Por ello, continuaba, era imprescindible «saber que los candidatos presentados son afectos y evitar en lo posible la presentación de candidatos desafectos».

Esta posición sobre la presentación de candidatos desafectos era precisamente la que se encontraba tras la segunda de las críticas que Rodrigo Vivar Téllez realizaba al plan de la Organización Sindical. En su opinión, la mera idea de que las candidaturas de concentración sindical que proponían Fermín Sanz Orrio y José María de Olazábal incluyesen en su seno a «elementos extremistas» estaba llena de "peligros». A decir verdad, de acuerdo con las propias palabras del vicesecretario general del Movimiento, esos "peligros» eran principalmente tres. El primero tenía que ver con el hecho de que un posible triunfo de dichos «extremistas» pudiera ser interpretado como «un éxito político de los partidos de donde procedan». El segundo estaba relacionado con el temor del régimen a que el éxito electoral de esos individuos opositores les permitiese «incrustar una cuña dentro de los organismos municipales» que pudieran utilizar para socavar las bases del régimen desde dentro. Finalmente, el dirigente falangista temía que las organizaciones profesionales, administrativas y políticas acabaran en manos de lo que los líderes sindicales denominaban «familias trabajadoras», puesto que, normalmente, aquellas eran las «más fluctuantes en política, las más orientadas hacia la izquierda, las menos reflexivas y las más difíciles de controlar».

A pesar de todo, este conflicto entre la Vicesecretaría General del Movimiento y la Delegación Nacional de Sindicatos no pasó a mayores porque las elecciones municipales de 1946 nunca se celebraron. En realidad, nada se sabe sobre las causas de esa suspensión, pero no parece descabellado pensar que las 
dificultades internas y externas que atravesaba el régimen a finales de 1945 y principios de 1946 pudiesen haber influido de algún modo en esa decisión del régimen. Por lo que se refiere a la situación internacional, a finales de 1945 el régimen de Franco seguía siendo muy mal visto por los vencedores de la Segunda Guerra Mundial y todavía no estaba claro que no se fuese a tomar ninguna medida para derribarlo. De hecho, tras ser condenado por los aliados en las asambleas de San Francisco, Potsdam y Londres, la ONU condenó formalmente el régimen de Franco el 9 de febrero de 1946 y solicitó a los países miembros que retiraran a sus embajadores en España en diciembre de ese mismo año. Por esas mismas fechas, el régimen tampoco atravesaba su mejor momento a nivel interior. Por un lado, los monárquicos presionaban para que don Juan sustituyese a Franco al frente del Estado. Por otro, el maquis se había vuelto más poderoso con el regreso de muchos veteranos españoles de la Segunda Guerra Mundial, e incluso amenazaba con una invasión del país desde Francia. En ese contexto, no parece descabellado que cualquiera con poder y un mínimo de perspicacia dentro de los centros de decisión del régimen hubiese preferido esperar a que las cosas se calmasen antes de organizar unas elecciones en las que podían cristalizar todos esos conflictos en forma de candidaturas opositoras triunfantes, lo que hubiera desestabilizado al régimen en un momento crítico.

\section{CONCLUSIONES}

A mediados de 1945 FET-JONS no atravesaba por su mejor momento. En mayo de 1945 las potencias del Eje habían sido derrotadas por los Aliados. Dos meses más tarde Franco se había visto obligado a tomar una serie de medidas de carácter cosmético que le permitiesen iniciar su adaptación al nuevo contexto internacional. Una de esas medidas consistió en apartar a Falange del primer plano de la política nacional. Sin embargo, eso no fue todo, puesto que otra de aquellas decisiones de carácter propagandístico fue la de aprobar la celebración de elecciones municipales a través de las cuales elegir a los concejales y fijar la fecha de su primera celebración en marzo de 1946. Desde la perspectiva del partido único, esta última medida no solo iba contra el credo político de la gran mayoría de los grupos que lo integraban, sino que también suponía una amenaza para el principal bastión de poder que éste todavía conservaba, la Administración periférica.

Sin embargo, Falange no permaneció pasiva ante un contexto tan adverso para sus intereses, como hubiese sido esperable de una organización políticamente acabada. Por el contrario, reaccionó de inmediato utilizando todos los 
recursos a su alcance no solo con el objetivo de evitar salir malparada de semejante coyuntura, sino para aprovecharse de ella con el fin de consolidar su poder. Para ello, FET-JONS diseñó una estrategia que le permitió intervenir en todas las etapas del proceso de organización de las futuras elecciones, desde la configuración de las juntas municipales y provinciales del censo hasta la selección de los candidatos, pasando por la creación de los censos electorales. La organización que se encargó de llevar el peso de dicha intervención fue la Organización Sindical, muy posiblemente como consecuencia del éxito que había tenido en la organización de las elecciones sindicales de 1944.

Dejando a un lado el hecho de que las elecciones municipales de 1946 nunca llegaron a celebrarse, el mecanismo de intervención en todas las fases de su organización que diseńó Falange y la forma en la que lo puso en práctica pusieron de manifiesto que a la altura de finales de 1945 el partido no era ni mucho menos una organización acabada, carente de pulso y de proyecto. Por el contrario, demostró tener un poderoso aparato institucional perfectamente arraigado dentro del régimen y con una gran coordinación entre los organismos nacionales y los periféricos. No obstante, eso no quiere decir que no existieran problemas dentro del mismo. En este sentido, su intento de intervenir en las elecciones de 1946 puso de manifiesto especialmente dos. En primer lugar, su dificultad para transmitir ese poder y esa coordinación institucional a la sociedad en general y a sus bases en particular. En segundo lugar, la diferencia de criterios entre la Delegación Nacional de Sindicatos y la Vicesecretaría General del Movimiento con respecto a cuáles debían ser las bases sociales sobre las que el partido debía asentar su poder.

\section{Bibliografía}

Braga da Cruz, M. (1988). O partido e o estado no salazarismo. Lisboa: Presença.

Cue, G. (1977). Las elecciones sindicales. Historia 16, 2, 94-108.

Domper Lasús, C. (2017). El partido único y las elecciones en la España franquista. Un análisis local a través del caso de Aragón, 1948-1973. Historia 396, 7 (2), 399-428.

Giménez Martínez, M. Á. (2012). Las Cortes Españolas en el régimen de Franco: nacimiento, desarrollo y extinción de una cámara orgánica. Madrid: Congreso de los Diputados.

Jessen, R. y Richter, H. (2011). Non-Competitive elections in 20th Century dictatorships: some questions and general considerations. En R. Jessen y H. Richter (eds.). Voting for Hitler and Stalin. Elections Under 20th Century Dictatorships (pp. 9-36). Frankfurt: Campus Verlag.

Marín, M. (2013a). Falange y poder local. En M. Á. Ruiz Carnicer (ed.). Falange. Las culturas politicas del fascismo en la España de Franco, 1936-1975 (pp. 231-252). Zaragoza: Institución «Fernando el Católico». 
- (2013b). Los gobernadores civiles del franquismo, 1936-1963. Historia y Politica, 29, 269-299.

- (2000). Els ajuntaments franquistes a Catalunya: política $i$ administració municipal, 1938-1979. Lleida: Pages.

Martínez Ovejero, A. (2008). ¡La Falange convoca elecciones! Las elecciones sindicales de 1944, significacion politica general del primer proceso electoral del franquismo, desde la realidad de una ciudad industrial y minera como Cartagena. En C. Navajas Zubeldia y D. Iturriaga Barco (coords.). Crisis, dictaduras, democracias. Actas del I Congreso Internacional de Historia de Nuestro Tiempo (pp. 191-208). Logrońo: Universidad de La Rioja.

Miranda, J. A. y Pérez, J. F. (1992). Actitudes falangistas ante las elecciones municipales (1948-1957). Anales de la Universidad de Alicante. Historia Contemporánea, 8-9, 139-147.

Molinero, C. e Ysas, P. (2008). La anatomía del franquismo. De la supervivencia a la agonia, 1945-1977. Barcelona: Crítica.

Moreno Fonseret, R. (ed.) (2003). Plebiscitos y elecciones en las dictaduras del sur de Europa (siglo XX). Alcoy: Marfil.

Reis Santos, J. (2011). Salazar e as eleiçoes. Un estudo sobre as eleiçoes gerais de 1942. Lisboa: Assembleia da Republica.

Rodríguez Barreira, Ó. (2007). Poder y actitudes sociales durante la postguerra en Almería (1939-1953). Almería: Universidad de Almería.

Ruiz Carnicer, M. Á. (1999). Falange en la penumbra: FET y de las JONS entre la rebelión y la resignación, 1945-1951. En Tiempos de silencio: actas del IV Encuentro de Investigadores del Franquismo (pp. 257-264). Valencia: Fundació d'Estudis i Iniciatives Sociolaborals.

Sanz Hoya, J. (2010). Jerarcas, caciques y otros camaradas. El estudio de los poderes locales en el primer franquismo. Historia del Presente, 15, 9-26.

- (2013). Falangismo y dictadura. Una revisión de la historiografía sobre el fascismo español. En M. Á. Ruiz Carnicer (ed.). Falange. Las culturas politicas del fascismo en la España de Franco, 1936-1975 (pp. 25-60). Zaragoza: Institución «Fernando el Católico».

- (2014). El asalto falangista a los gobiernos civiles. La politica de unión de los cargos de gobernador y jefe provincial de FET-JONS (1938-1945). Alcores, 18, 193-212.

Sanz-Orrio Arraiza, E. (2009). Fermin Sanz-Orrio. Luchador por la justicia social. Astorga: Editorial Akrón; CSED.

Swearer, H. R. (1961). The Functions of Soviet Local Elections. Midwest Journal of Political Science, 5, 129-149. Disponible en: https://doi.org/10.2307/2109266.

Thomàs, J. M. (2001). La Falange de Franco. Fascismo y fascistización en el régimen franquista (1937-1945). Barcelona: Plaza y Janés. 